\title{
The prediction of success in kickboxing based on the analysis of morphofunctional, physiological, biomechanical and psychophysiological indicators
}

\author{
Podrigalo L.V. ${ }^{1 \mathrm{ABCDE}}$, Volodchenko A.A. ${ }^{2 \mathrm{ABCDE}}$, Rovnaya O.A. ${ }^{1 \mathrm{ABCDE}}$, Podavalenko O.V. ${ }^{1 \mathrm{ABCDE}}$, Grynova T.I. ${ }^{3 \mathrm{ABCDE}}$ \\ ${ }^{1}$ Department of Human Hygiene and Physiology, Kharkov State Academy of Physical Culture, Ukraine \\ ${ }^{2}$ Department of Weightlifting and Boxing, Kharkov State Academy of Physical Culture, Ukraine \\ ${ }^{3}$ Department of Winter Sports, Cycling and Tourism, Kharkov State Academy of Physical Culture, Ukraine
}

Authors' Contribution: A - Study design; B - Data collection; C - Statistical analysis; D - Manuscript Preparation; E - Funds Collection.

\begin{abstract}
Purpose: $\quad$ To substantiate and develop a methodology for predicting success in kickboxing on the basis of analysis of morphofunctional, physiological, biomechanical and psychophysiological indicators.

Material: $\quad$ it was examined athletes of kickboxing ( $n=185$, age $18.58 \pm 0.46$ years). It was studied the features of physical development $(n=18)$. The main biomechanical parameters $(n=45)$ were determined. Goniometric indices of limb joints $(n=29)$ were studied. It was studied the features of psychophysiological reactions $(n=76)$. The adaptive capabilities of the cardiovascular system were studied $(n=17)$. The prognostication is carried out by means of a sequential Wald procedure. Prognostic coefficients and their informativity were calculated.

Results: $\quad$ a prognostic table was developed containing the indicators of the functional state of kickboxing athletes. The table includes 31 criteria, the informativeness of which varied within $115,45-2,23$. The content of the forecast consists in: an evaluation of the results; determination of the corresponding prognostic coefficient; summation of coefficients. The threshold was set at the level \pm 13 , which corresponds to a probability of $95 \%(p<0,05)$. Exceeding the positive threshold means a high level of success for the athlete. When the negative threshold is reached, the probability of success is low.

Conclusions: $\quad$ The proposed methodology is based on a sequential analysis of Wald. The technique is a simple, informative and objective tool for monitoring and predicting the status of athletes.

Keywords: $\quad$ kickboxing, forecast, success, morphofunctional, physiological, biomechanical, psychophysiological, indicators.
\end{abstract}

\section{Introduction}

Forecasting success in sports is one of the key scientific and practical tasks. Evaluation of the probability of high performance involves studying indicators that reflect the level of sportsmanship, identifying the most informative and establishing dependencies between them.

Forecasting success requires an integrated approach. Thus, Baláš J. et al. [1] found that strength and endurance of hands are the most informative predictors of alpinist skill. The high prognostic significance of hand strength is proven in swimmers [2].

Raysmith B.P. and Drew M.K. [3] determined the relationship between the failure of athletes and the burden of injury / illness. The authors used logistic regression. A curve analysis was conducted to determine the optimal threshold for the completion of the training week in order to maximize the chances of success.

Schick M.G. et al. [4] considered the physiological requirements for women - athletes of mixed martial arts. The conclusion is made about the importance of the development of speed and agility for success.

Buse G.J. et al. [5] note that the preparation of highlevel kickboxers should be based on a set of factors, including physical exertion, optimal rest and nutrition and psychological preparation. Training should influence the aerobic and anaerobic characteristics of athletes' metabolism.

Williams S. et al. [6] revealed clear negative

(c) Podrigalo L.V., Volodchenko A.A., Rovnaya O.A.,

Podavalenko O.V., Grynova T.I., 2018

doi:10.15561/20755279.2018.0108 associations between injuries and success in the team. The authors found that a moderate reduction in the burden of injuries can have a significant impact on the results of competitions for professional rugby union teams.

Hastie P.A. et al. [7] found that the use of graduated competition would increase the opportunities for participation in the game and the successes of the athletes of higher and lower levels.

Iavorskaia T.E. [8] proposed to use a number of statistical methods (regression, vector, matrix, dispersion and factor analysis, the theory of multidimensional linear regression in Euclidean space) to predict performance in sports.

Linear regression analysis confirmed that the pick and roll could be predicted in the final classification of the teams [8]. Conclusively, coaches of the high level European clubs should focus on training the players to the most effective phases of the pick.

Winter C. and Pfeiffer M. [9] considered important theoretical requirements for the analysis of sports games (for example, interaction between the two parties, procedural sequence of actions or the value of tactical behavior), the value of the introduced parameters, called tactical metrics, is illustrated. Discriminant analysis, based on the values of factors, leads to a correct classification of $64,8 \%$, identifying winners and losers. This successful discrimination reveals the connection between the success of the match and the presented metrics.

By considering the important theoretical requirements for the analysis of sports games (like the interaction 
between two parties, the procedural sequence of action or the significance of tactical behaviour) the meaning of the introduced parameters, called tactical metrics, is illustrated. Discriminant analysis based on the factor values leads to a correct classification of $64.8 \%$ identifying winners and losers. This successful discrimination reveals a connection between match success and the presented metrics.

Sport-confidence is considered a critical success factor for sport performers at all levels [10]. Researchers have suggested that sport-confidence is a multidimensional rather than a unidimensional construct, and the sportconfidence model identified three types of sportconfidence (i.e., physical skills and training, cognitive efficiency, and resilience) that are important for success in sport.

Zaporozhanov V.A. et al. [11] confirmed the feasibility of the metric method of calculating the reliability of the results of control measurements used to diagnose psychophysiological fitness and predict the growth of skill. Metric estimates of the reliability of measurements are calculated - stability, consistency, informative data of the control data. These estimates are used for the current diagnosis and prognosis of the sports capabilities of the examined

The interaction between teams' behaviour is from high relevance for success in sports games [12]. Odds ratio analysis revealed advantageous defensive tactics against specific offensive behaviour. Summarizing, results indicate that artificial neural networks are appropriate to model the interaction between teams based on players' positions.

In sports, fast and accurate execution of movements is required. It has been shown that implicitly learned movements might be less vulnerable than explicitly learned movements to stressful and fast changing circumstances that exist at the elite sports level. Present findings may be important for sports because children with superior implicit learning abilities in early learning phases may be able to learn more (durable) motor skills in a shorter time period as compared to other children.

Thus, the available literature data indicate the possibility of predicting success in sports based on the results of morphological, functional, physiological and psychophysiological data. The forecasting tool is the mathematical methods and used in statistics. However, in kickboxing, this problem does not yet have a final solution. This also determined the relevance of this study.

The aim of the work was to develop a methodology for predicting success in kickboxing based on a complex of morphofunctional, physiological, biomechanical and psychophysiological indicators.

\section{Materials and methods.}

Participants. The results of a survey of kickboxing athletes ( $\mathrm{n}=185$, age $18.58 \pm 0.46$ years) were used as a main material. The features of physical development $(n=18)$ were studied. The main biomechanical parameters $(n=45)$ were determined. Goniometric indices of limb joints $(n=29)$ were studied. We studied the features of psychophysiological reactions $(n=76)$. The adaptive capabilities of the cardiovascular system $(n=17)$ have been studied.

Organization of the study. All athletes were divided into groups, depending on the type of martial arts. Allocated group: athletes kickboxing; wrestlers; athletes karate, taekwondo, etc. [14-16].

In assessing the characteristics of physical development, kickboxing athletes were divided into two groups, depending on the level of skill. The first group masters and candidates for master of sports, the second group - amateurs and athletes up to 1 category inclusive [17].

In assessing the adaptive capabilities of the cardiovascular system, kickboxing athletes were divided into two groups, depending on the type of reaction. The first group includes athletes with a normotonic type of reaction. The second group includes athletes whose reaction type was different from normotonic [18].

As a tool for solving the prognostic problem, a sequential Wald procedure was applied [19]. As boundary values, the mean values of the studied indices in the groups were chosen. Then, the probability of a smaller or larger value of the indicators relative to the average values was determined. Then the prognostic coefficients and the informativeness of the traits studied were calculated.

The characteristics in the table are arranged in decreasing order of informativeness. The value of informativity less than 2,0 was considered insignificant. Indicators with this or a lesser value were not included in the table. In the case of the same informative value, the order of location is determined randomly.

Statistical analysis. The analysis of the obtained data was carried out with the help of licensed packages of Excel spreadsheets. Prognostic coefficients were calculated using the formula:

$$
\mathrm{PF}=10 \times \lg \left[\mathrm{p}\left(\mathrm{D}_{1} / \mathrm{S}\right) / \mathrm{p}\left(\mathrm{D}_{2} / \mathrm{S}\right)\right]
$$

where $P F$ is the prognostic factor, $p\left(D_{1} / S\right)$ is the probability of the presence of the characteristic, $p\left(D_{2} / S\right)$ is the probability of the absence of the characteristic.

The multiplication factor by 10 is introduced in order to the PF to be an integer. This facilitates the forecast procedure.

Informativeness was calculated in accordance with the Kullback formula:

$$
\mathrm{I}=\mathrm{PF} \times 0.5 \times\left[\mathrm{p}\left(\mathrm{D}_{1} / \mathrm{S}\right)-\mathrm{p}\left(\mathrm{D}_{2} / \mathrm{S}\right)\right]
$$

where I is informative character of the characteristic. The other notation is the same as in the previous formula.

\section{Results.}

The developed prognostic table combines indicators reflecting the peculiarities of the functional state of kickboxing athletes. It includes 31 indicators. The signs are included taking into account the reliability of the 
differences and the informativeness of the evaluated traits. The signs describe the physical, goniometric, biomechanical and functional indices of athletes. A large number of prognostic criteria can significantly increase the probability of obtaining a certain forecast. The results are shown in Table 1.

Analysis of the indicators (Table 1) shows that the most important for predicting success in kickboxing are: biomechanical indicators (8 criteria), goniometric indicators (7 criteria) and anthropometric indicators (7 criteria). Analysis of these criteria proves their importance as predictors of success in kickboxing. Thus, an increase in the amplitude of movements in the shoulder and elbow joints reflects the increased possibility of applying strong and qualitative strokes. This is an important factor in success in kickboxing.

Anthropometric indicators (circumference of the shoulder and wrist) illustrate the level of development of the muscles of the extremities. This should also be evaluated as evidence of the possibility of inflicting heavy

Table 1. Forecasting the success of kickboxing athletes

\begin{tabular}{|c|c|c|c|}
\hline \multirow{2}{*}{ Index } & \multicolumn{2}{|c|}{ Forecasting coefficients } & \multirow{2}{*}{ Informativeness } \\
\hline & Existing & Lack & \\
\hline Bending of the right shoulder joint more than $190^{\circ}$ & 5 & -3 & 115.45 \\
\hline Diastolic pressure at rest in less than $69 \mathrm{~mm} \mathrm{Hg}$ & 3 & -2 & 52.98 \\
\hline The thickness of the left hand is larger $2 \mathrm{~cm}$ & 2 & -4 & 40.51 \\
\hline $\begin{array}{l}\text { Amplitude of the } \mathrm{R} \text { wave of the electrocardiogram (ECG) at rest is } \\
\text { greater than } 0,419 \mathrm{mV}\end{array}$ & 2 & -4 & 36.44 \\
\hline Extension of the right wrist joint more than $58^{\circ}$ & 2 & -2 & 31.44 \\
\hline Leaving the left shoulder joint more than $174^{\circ}$ & 2 & -4 & 26.65 \\
\hline Vital lung capacity more than 3,2 I & 2 & -2 & 24.65 \\
\hline Thigh mass more than 9,37 kg & 2 & -2 & 23.46 \\
\hline Weight of forearm more than $1,07 \mathrm{~kg}$ & 2 & -2 & 23.46 \\
\hline Shoulder weight more than $1,75 \mathrm{~kg}$ & 2 & -2 & 23.46 \\
\hline $\begin{array}{l}\text { The main central moment of inertia of the forearm relative to the } \\
\text { sagittal axis is greater than } 58,36 \mathrm{~kg}^{*} \mathrm{~cm}^{2}\end{array}$ & 2 & -2 & 23.46 \\
\hline $\begin{array}{l}\text { The central central moment of inertia of the tibia with respect to } \\
\text { the longitudinal axis is greater than } 56,88 \mathrm{~kg}^{*} \mathrm{~cm}^{2}\end{array}$ & 2 & -2 & 23.46 \\
\hline $\begin{array}{l}\text { The main central moment of inertia of the thigh relative to the } \\
\text { longitudinal axis is greater than } 325,96 \mathrm{~kg}^{*} \mathrm{~cm}^{2}\end{array}$ & 2 & -2 & 23.46 \\
\hline $\begin{array}{l}\text { The main central moment of inertia of the shoulder relative to the } \\
\text { longitudinal axis is greater than } 34,24 \mathrm{~kg}^{*} \mathrm{~cm}^{2}\end{array}$ & 2 & -2 & 23.46 \\
\hline Bending of the right elbow joint more than $120^{\circ}$ & 2 & -2 & 19.70 \\
\hline Extension of the right shoulder joint more than $72^{\circ}$ & 2 & -2 & 19.70 \\
\hline Bringing the right shoulder joint more than $30^{\circ}$ & 2 & -2 & 19.70 \\
\hline Circumference of the right shoulder more than $32,4 \mathrm{~cm}$ & 2 & -2 & 19.57 \\
\hline Circumference of the left shoulder more than $32,3 \mathrm{~cm}$ & 2 & -2 & 19.57 \\
\hline Flexion of the left knee joint more than $77^{\circ}$ & 2 & -1 & 15.41 \\
\hline $\begin{array}{l}\text { The main central moment of inertia of the forearm relative to the } \\
\text { longitudinal axis is greater than } 10,22 \mathrm{~kg}^{*} \mathrm{~cm}^{2}\end{array}$ & 2 & -1 & 13.52 \\
\hline Speed of the line more $136 \mathrm{~mm} / \mathrm{s}$ & 1 & -2 & 12.85 \\
\hline The response time of choice is less than $576 \mathrm{~ms}$ & 1 & -1 & 11.56 \\
\hline The QT interval value of the ECG after the load is less than $269 \mathrm{~ms}$ & 1 & -4 & 10.41 \\
\hline $\begin{array}{l}\text { Resistance to knocking down signals of simple motor skills more } \\
\text { than } 82 \%\end{array}$ & 1 & -1 & 5.86 \\
\hline Shoulder width more than $42,4 \mathrm{~cm}$ & 1 & -1 & 5.38 \\
\hline Circumference of the right wrist more than $17,3 \mathrm{~cm}$ & 1 & -1 & 4.40 \\
\hline Circumference of the left wrist is larger than $16,8 \mathrm{~cm}$ & 1 & -1 & 4.40 \\
\hline Heart rate at a load of less than 130 beats per minute & 1 & -1 & 2.56 \\
\hline $\begin{array}{l}\text { The amplitude of the R wave of the ECG after loading is greater } \\
\text { than } 0.22 \mathrm{mV}\end{array}$ & 1 & -1 & 2.56 \\
\hline $\begin{array}{l}\text { The number of touches of simple motor skills is more than } 27 \text { in } 10 \\
\text { seconds }\end{array}$ & 1 & -1 & 2.23 \\
\hline
\end{tabular}


strikes.

The mass of the segments of the limbs and the main central moments of their inertia relative to the sagittal and longitudinal axes also illustrate the biomechanical characteristics of shock actions in kickboxing.

An important predictor of success in kickboxing should be recognized the high adaptive potential of the organism, the expansion of the functionality of athletes. This is evidenced by the value of lung capacity: an indicator reflecting the increased functional state of the respiratory system of athletes.

The importance of increasing the adaptive capacity for success in kickboxing is confirmed by the presence of five indicators of the state of the cardiovascular system in the table. They illustrate the dynamics of heart rate, blood pressure (BP) and ECG parameters (at rest, under load and in the recovery period). The developed prognostic technique proves the importance of evaluating the reaction of athletes to metered physical loads. Athletes with a high level of adaptive capabilities have a high probability of success.

The last four indicators of the prognostic table belong to the group of psychophysiological indicators. They illustrate the speed of reaction to various stimuli, the level of attention and coordination. These qualities are prognostically important for success in kickboxing.

These tables confirm the high information value of such indicators. The value of the indicators ranged from 115,45 to 2,23 . There was also a coincidence of this parameter. Thus, for seven biomechanical parameters, the informativeness was 23,46. For three goniometric indicators, the informativeness was 19,70 . For shoulder circumferences, the informativeness was 19,57. For the circumference of the wrist, the informativeness was 4,40 . For the heart rate and the amplitude of the $\mathrm{R}$ wave, the informativeness was 2,56. In these cases, the order of presentation of the characteristics in the table was determined randomly.

The developed table allows to carry out the forecast of sports success of kickboxing athletes. The content of the forecast consists of an assessment of their results, determination of the corresponding prognostic coefficient and their summation. The thresholds were set at the level \pm 13 , corresponding to a probability of $95 \%(\mathrm{p}<0.05)$.

Exceeding the threshold of +13 means a high level of success for the athlete in kickboxing. If the opposite maximum values are reached, the probability of success is extremely low. If the prediction procedure is completed and none of the maximum values is reached, then a decision is made about an undefined forecast. In this case, research is needed to obtain additional information.

The proposed forecasting scheme has a universal nature and can be used at various stages of assessing the functional state of athletes. As a significant advantage of the developed methodology, it should be noted that the overwhelming number of criteria are manageable. Such criteria can change in the process of optimally constructed training.

Depending on the purpose, it makes sense to make appropriate changes in the forecast table (that is, the number of methods used). So, at the stage of the preliminary forecast it makes sense to conduct: anthropometric research; analysis of goniometric indices of limb joints; psychophysiological research; determine the response to standard loads. This gives the coach the maximum information about the athlete's functional state. Also allows to determine the perspective of the athlete and the introduction of individual corrections in the training program.

For the current forecast of training construction, tolerance to physical loads has the greatest importance. Therefore, this prediction can be based on a standard ergonomic and biomechanical study. A forecast of competitive success requires a comprehensive assessment with the application of all groups of criteria.

\section{Discussion.}

The research scheme suggested an analysis of a complex of diverse indicators. This allows to significantly increase the efficiency of the forecast and coincides with the opinion of many specialists. Thus, Slimani M. et al. [20] analysed the anthropometric, physiological and psychological characteristics of kickboxers. The features of the constitution of kickboxers of different levels, the status of the adaptive status of the cardiorespiratory system are established. A high level of skill is combined with a good development of the muscular strength of the limbs, a high level of self-confidence, working capacity and the ability to adapt. Specific psychophysiological characteristics affect the capacity and productivity of the activity and should be taken into account in the preparation

Similar data in many respects are given by Ouergui I. et al. [21]. The authors investigated the hormonal, physiological and physical changes in the body of kickboxers during a real fight. The effectiveness of the tests used as tools for assessing athletes' preparedness is proved.

Podrigalo L.V. et al. [22] proposed a comprehensive approach to assessing the success of athletes in armwrestling.

In our study, we used a comparison of athletes engaged in different types of martial arts. This approach is also widely used in modern scientific research. Thus, Bounty P.L. et al. [23] analysed literature on mixed martial arts (MMA). The authors emphasize the inadequacy of complex studies devoted to improving the success of athletes.

Comparison of the characteristics of athletes of different types of martial arts allows: to assess their specificity; highlight the main factors that affect success. Our studies have proved the validity of such a campaign in the analysis of biomechanical, psychophysiological and goniometric indicators [14-16]. This served as the basis for including these groups in the prognostic table.

The high informativeness of goniometric indicators is confirmed by the data of other studies. Thus, Machado S. et al. [24] compared isokinetic indicators of the knee 
joint of kickboxing and taekwondo athletes. The authors used the Biodex Multi-Joint System dynamometer 3. The proximity of training in these sports caused the absence of differences in the maximum torque and the relative balance of flexor agonists and extensor muscles.

Similar results were obtained by Szafrański K. et al. [25]. The authors compared the moments of muscular strength of flexors and extensors of the knee joint in static and isokinetic conditions in kickboxers and athletes. The possibility of using these indicators for the prognosis in martial arts has been confirmed.

Similar results were obtained by Machado S. M. et al. [26]. The authors analysed the efficiency of flexion and extension of the knee in athletes' kickboxing and taekwondo. All have confirmed the dependence of power and torque on training experience. It is proved that the ability to increase muscle mass is associated with the energy capacity of contraction and with motor coordination.

Catikkas F. et al. [27] note an insufficient number of studies of kinantropometric (Kinanthropometric) features of Turkish martial arts athletes. The authors studied the physique of athletes in karate, taekwondo, kickboxing and judo. It was established that the mesomorphic component of the somatotype is dominant. The body mass index was related to the average values, the specific gravity of the fat was low. Informative indicators were the width of shoulders and hips. These data coincide with our results.

Podrigalo L.V. et al. [28] used the method of indexes to predict the success of athletes of single combats. The revealed differences illustrate the specificity of sports, the differences in the physique of fighters and athletes of martial arts.
Inclusion in the number of prognostic indicators of the results of psychophysiological studies is also due to their high informativeness. Thus, Slimani M. et al. [19] evaluated the results of functional tests of highlevel kickboxers during the national championship. The athletes were divided into groups depending on the results of the fights. The winners had significantly better mental performance. The presence of regression links of success was confirmed according to the results of this test. It is offered to use mental working capacity for the forecast of success in kickboxing.

Volodchenko O. et al. [15] confirmed the presence of differences in the psychophysiological status of athletes' kickboxing, wrestling, karate, taekwondo. The established features reflect the specifics of sports and should be used as predictors of success. This served as the basis for including this group of criteria in the prognostic table.

\section{Conclusions.}

Thus, the conducted studies allowed to substantiate and develop a comprehensive methodology for predicting success in kickboxing. The technique is based on the Wald's sequential analysis procedure. The proposed methodology can be used for forecasting at various stages of preparation. The technique is a simple, adequate and informative tool for monitoring the functional state of kickboxing athletes.

\section{Conflicts of interest}

The authors declare that there is no conflict of interests.

\section{References}

1. Baláš J, Pecha O, Martin AJ, Cochrane D. Hand-arm strength and endurance as predictors of climbing performance. European Journal of Sport Science. 2012;12(1):16-25. doi:1 0.1080/17461391.2010.546431

2. Dummer GM, Clarke DH, Vaccaro P, Vander Velden L, Goldfarb AH, Sockler JM. Age-Related Differences in Muscular Strength and Muscular Endurance among Female Masters Swimmers. Research Quarterly for Exercise and Sport, 1985; 56(2), 97-102. doi:10.1080/02701367.1985.10 608442

3. Raysmith BP, Drew MK. Performance success or failure is influenced by weeks lost to injury and illness in elite Australian track and field athletes: A 5-year prospective study. Journal of Science and Medicine in Sport. 2016;19(10):778783. doi:10.1016/j.jsams.2015.12.515

4. Schick MG, Brown LE, Schick EE. Strength and Conditioning Considerations for Female Mixed Martial Artists: Strength and Conditioning Journal, 2012;34:66-75. doi:10.1519/ SSC.0b013e31824443e2

5. Buse GJ, Santana JC. Conditioning Strategies for Competitive Kickboxing: Strength and Conditioning Journal, 2008;30:42-8. doi:10.1519/SSC.0b013e31817f19cd

6. Williams S, Trewartha G, Kemp SPT, Brooks JHM, Fuller $\mathrm{CW}$, Taylor AE, et al. Time loss injuries compromise team success in Elite Rugby Union: a 7-year prospective study. British Journal of Sports Medicine. 2016;50(11):651-656. doi:10.1136/bjsports-2015-094798

7. Hastie PA, Ward JK, Brock SJ. Effect of graded competition on student opportunities for participation and success rates during a season of Sport Education. Physical Education and Sport Pedagogy. 2017;22(3):316-327. doi:10.1080/1740898 9.2016.1203888

8. Marmarinos C, Apostolidis N, Kostopoulos N, Apostolidis A. Efficacy of the "Pick and Roll" Offense in Top Level European Basketball Teams. Journal of Human Kinetics. 2016;51(1):121-129. doi:10.1515/hukin-2015-0176

9. Winter C, Pfeiffer M. Tactical metrics that discriminate winning, drawing and losing teams in UEFA Euro 2012 (R). Journal of Sports Sciences. 2016;34(6):486-492. doi:10.108 0/02640414.2015.1099714

10.Machida M, Otten M, Magyar TM, Vealey RS, Ward RM. Examining multidimensional sport-confidence in athletes and non-athlete sport performers. Journal of Sports Sciences. 2017;35(5):410-418. doi:10.1080/02640414.2016.1167934

11.Zaporozhanov VA, Borachinski T. Empirical reliability of diagnostic and prognostic assessments of the physical condition of children involved in sports. Pedagogics, psychology, medical-biological problems of physical training and sports, 2012;11: 38 - 42. doi:10.6084/m9.figshare.97355

12.Schrapf N, Alsaied S, Tilp M. Tactical interaction of offensive and defensive teams in team handball analysed by artificial neural networks. Mathematical and Computer Modelling of Dynamical Systems. 2017;23(4):363-371. doi:10.1080/1387 


\subsection{7 .1336733}

13. Verburgh L, Scherder EJA, van Lange PAM, Oosterlaan J. The key to success in elite athletes? Explicit and implicit motor learning in youth elite and non-elite soccer players. Journal of Sports Sciences. 2016;34(18):1782-1790. doi:10. 1080/02640414.2015.1137344

14.Podrigalo LV, Volodchenko AA, Rovnaya OA, Stankiewicz B. Analysis of martial arts athletes' goniometric indicators. Physical education of students, 2017; 21(4): 182-188. doi:10.15561/20755279.2017.0406

15. Volodchenko O, Podrigalo L, Aghyppo O, Romanenko $\mathrm{V}$, Rovnaya O. Comparative Analysis of a functional state of martial arts athletes. Journal of Physical Education and Sport, 2017; 17 Supplement issue 4, 2142 - 2147. doi:10.7752/jpes.2017.s4220

16.Podrigalo LV, Volodchenko AA. Comparative analysis of biomechanical aspects of kickboxing and other single matches. Visnik Chernigivs'kogo nacional'nogo pedagogichnogo universitetu imeni T.G. Shevchenka, 2016; 139(1): 145 - 149. (in Ukrainian)

17. Volodchenko AA. Features of the physical development of kick-boxing athletes of different levels of training. Naukovopedagogichni problemi fizichnoi kul 'turi, 2017;5(87): 24-28. (in Russian)

18. Podrigalo LV, Volodchenko AA, Rovnaya OA, Ruban LA, Sokol KM. Analysis of adaptation potentials of kick boxers' cardio-vascular system. Pedagogics, psychology, medicalbiological problems of physical training and sports, 2017; 21(4): 185-191. doi:10.15561/18189172.2017.0407

19.Antomonov MIu. Processing and analysis of biomedical data. Kiev; 2006. (in Russian)

20.Slimani M, Miarka B, Briki W, Cheour F. Comparison of Mental Toughness and Power Test Performances in HighLevel Kickboxers by Competitive Success. Asian Journal of Sports Medicine, 2016;Inpress. doi:10.5812/asjsm.30840

21.Ouergui I, Houcine N, Marzouki H, Davis P, Zaouali M, Franchini E, et al. Development of a Noncontact Kickboxing Circuit Training Protocol That Simulates Elite
Male Kickboxing Competition. Journal of Strength and Conditioning Research 2015;29:3405-11. doi:10.1519/ JSC.0000000000001005

22.Podrigalo LV, Galashko M N, Iermakov SS, Rovnaya OA, Bulashev AY. Prognostication of successfulness in armwrestling on the base of morphological functional indicators' analysis. Physical education of students, 2017; 21(1): 46-51. doi:10.15561/20755279.2017.0108

23.Bounty PL, Campbell BI, Galvan E, Cooke M, Antonio J. Strength and Conditioning Considerations for Mixed Martial Arts. Strength and Conditioning Journal, 2011;33:56-67. doi:10.1519/SSC.0b013e3182044304

24.Machado S, Souza RA, Simão A, Jerônimo D, Silva N, Osorio $\mathrm{R}$, et al. Comparative study of isokinetic variables of the knee in taekwondo and kickboxing athletes. Fitness \& Performance Journal, 2009;8:407-11. doi:10.3900/ fpj.8.6.407.e

25.Szafrański K, Boguszewski D. Comparison of maximum muscle torque values of extensors and flexors of the knee joint in kickboxing and taekwondo athletes. Journal of Combat Sports and Martial Arts, 2015;6:59-62. doi:10.5604/20815735.1193625

26.Machado SM, Osório RAL, Silva NS, Magini M. Biomechanical analysis of the muscular power of martial arts athletes. Medical \& Biological Engineering \& Computing, 2010;48:573-7. doi:10.1007/s11517-010-0608-z

27.Catikkas F, Kurt C, Atalag O. Kinanthropometric attributes of young male combat sports athletes. Collegium antropologicum, 2013; 37, 1365-8.

28.Podrigalo LV, Iermakov SS, Jagiełło W. Special indices of body composition as a criterion of somatic development of martial arts practitioners. Arch Budo Sci Martial Art Extreme Sport, 2017; 13: 5-12.

29. Slimani M, Chaabene H, Miarka B, Chamari K. The Activity Profile of Elite Low-Kick Kickboxing Competition. International Journal of Sports Physiology and Performance, 2017;12:182-9. doi:10.1123/ijspp.2015-0659

Information about the authors:

Podrigalo L.V. (Corresponding author); http://orcid.org/0000-0002-7893-524X; I.podrigalo@mail.ru; Department of Human Hygiene and Physiology, Kharkov State Academy of Physical Culture; Klochkovskaya str. 99, Kharkov, 61022, Ukraine.

Volodchenko A.A.; http://orcid.org/0000-0002-1189-3524; olodchenko_aa@mail.ru; Department of Weightlifting and Boxing, Kharkov State Academy of Physical Culture; Klochkovskaya str. 99, Kharkov, 61022, Ukraine.

Rovnaya O.A.; http://orcid.org/0000-0003-1519-5632; ovnayaolga@mail.ru; Department of Human Hygiene and Physiology, Kharkov State Academy of Physical Culture; Klochkovskaya str. 99, Kharkov, 61022, Ukraine.

Podavalenko O.V.; http://orcid.org/0000-0001-9143-3351; oblcz@ya.ru; Department of Human Hygiene and Physiology, Kharkov State Academy of Physical Culture; Klochkovskaya str. 99, Kharkov, 61022, Ukraine.

Grynova T.I.; http://orcid.org/0000-0002-8768-0672; tgrynova88@gmail.com; Department of Winter Sports, Cycling and Tourism, Kharkov State Academy of Physical Culture; Klochkovskaya str. 99, Kharkov, 61022, Ukraine.

Cite this article as: Podrigalo LV, Volodchenko AA, Rovnaya OA, Podavalenko OV, Grynova TI.. The prediction of success in kickboxing based on the analysis of morphofunctional, physiological, biomechanical and psychophysiological indicators. Physical education of students, 2018;22(1):51-56. doi:10.15561/20755279.2018.0108

The electronic version of this article is the complete one and can be found online at: http://www.sportedu.org.ua/index.php/PES/issue/archive

This is an Open Access article distributed under the terms of the Creative Commons Attribution License, which permits unrestricted use, distribution, and reproduction in any medium, provided the original work is properly cited (http://creativecommons.org/licenses/by/4.0/deed.en).

Received: 19.12 .2017

Accepted: 12.01.2018; Published: 27.02.2018 